\title{
Investigación, ciencia y tecnología e innovación
}

\author{
Raúl Zelaya, ${ }^{1}$ Mario Lanza ${ }^{2}$
}

\section{CT/ En su opinión, ¿qué debe hacer la universidad para construir cultura de innovación?}

RZI El trabajo es integrado en todas las facetas de la universidad. Los profesores deben entender que la instrucción universitaria debe estar enfocada en el análisis de procesos y la reflexión crítica que desarrolle la parte innovadora del cerebro y menos en recetas que el estudiante solamente repita en sus pruebas. Lo anterior es un cambio paradigmático profundo que comienza en el pensamiento de los mismos catedráticos. Luego, el esfuerzo de la universidad en trabajos de vinculación es clave para que la educación sea en base de la realidad nacional y el enfoque en solución de problemas reales, combinado con ambientes de crítica constructiva e investigación aplicada.

ML/ La universidad debe comprometerse a fomentar los procesos de investigación e innovación en todos los ámbitos del quehacer universitario, especialmente en el aula de clases, promoviendo la creatividad de los docentes y de los estudiantes. También es importante desarrollar eventos, ciclos de conferencias, ferias científicas, publicaciones, eventos académicos, de divulgación y concientización sobre la innovación y la importancia de la gestión de la innovación en las organizaciones. Asimismo, considero importante incentivar con becas, viajes académicos y reconocimientos a los estudiantes y docentes que fomenten y participen activamente en procesos de investigación e innovación, así como promover el emprendedurismo y el desarrollo empresarial en la comunidad universitaria. Finalmente, recomendaría incluir en los planes de estudio de todas las carreras la asignatura de gestión de la innovación.

\section{CT/ ¿Qué tan relevante es la innovación en la calidad de la educación universitaria y el desarrollo económico y social del país?}

RZI Es clave, la innovación es la opción de buscar soluciones nuevas a los

Decano Académico de la EscuelaAgrícola Panamericana del Zamorano.

${ }^{2}$ Vicerrector de Innovación y Desarrollo de la Universidad José Cecilio del Valle. 
problemas de siempre. Si continuamos con las mismas recetas, los problemas continuarán ahí. No basta con copiar modelos de otros países, Honduras tiene que encontrar su propio modelo de desarrollo socioeconómico y la base de esto se encuentra en los profesionales y la academia, que debe reenfocar sus estrategias.

ML/ Actualmente la innovación es la clave para potenciar la calidad de la educación. La aplicación de modelos educativos innovadores, incluyendo el aprendizaje autónomo, autorregulado y basado en la experiencia, incorporando el uso de tecnologías de la información y comunicación en el aula de clases y fuera de ella, es vital para mejorar la calidad de la educación, por lo que la creatividad y la innovación juega un papel preponderante en los procesos de enseñanza-aprendizaje. De igual manera, la innovación tiene un impacto directo en el desarrollo económico y social del país, por lo que debería ser una prioridad nacional.

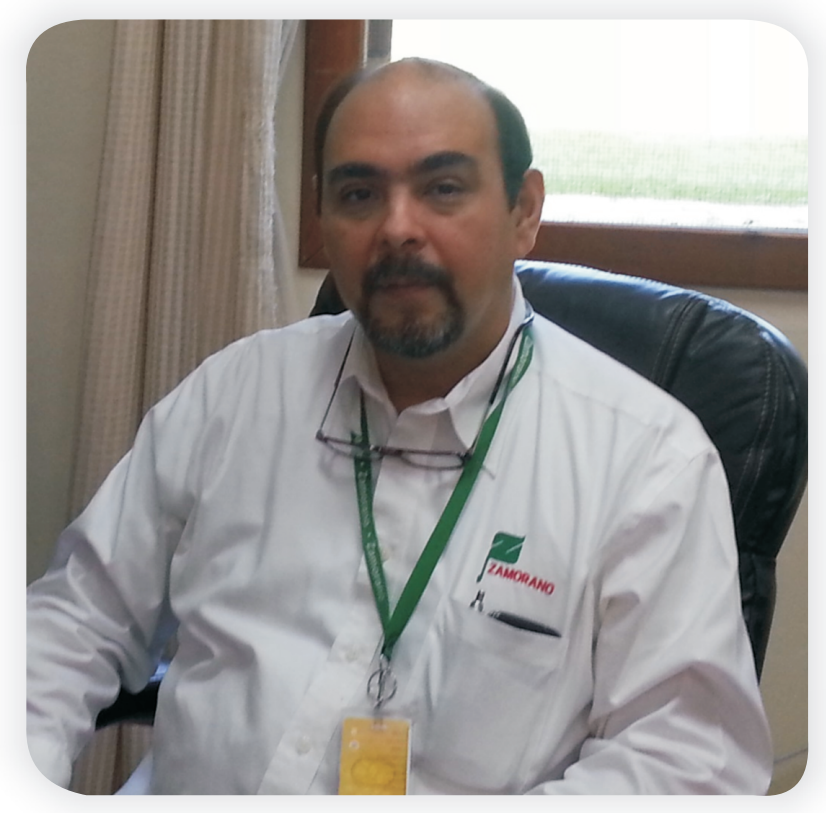

Raúl Zelaya

3. CT/ ¿Qué papel juega la investigación y el desarrollo tecnológico en un proceso sostenido de innovación?

RZI Es básico, las inversiones en investigación y desarrollo tecnológico en el 
país son extremadamente bajas. En consecuencia, todos los sectores públicos y privados deben entender que si no se invierte en soluciones, seguiremos la misma marcha hacia el continuo subdesarrollo.

ML/ La investigación y el desarrollo (l+D) son esenciales para los procesos de innovación (i), de tal manera que en la actualidad, las tres dimensiones están integradas en un solo proceso creativo $(1+D+i)$. En ese contexto, la investigación y el desarrollo tecnológico son indispensables para los procesos de innovación y la mejora continua de productos, procesos 0 servicios, potenciando la productividad y la competitividad del país en general y de las organizaciones en particular.

4. CT/ ¿Cree que en las universidades de Honduras existen condiciones políticas, estructurales, relacionales, tecnológicas y científicas para coadyuvar a la innovación y la competitividad del país?

RZI Desafortunadamente, aún no. Lo más complicado es cambiar la mentalidad de los funcionarios y del cuerpo docente, dejando los egoísmos a un lado, lo demás viene por añadidura. Las condiciones políticas adversativas no construyen y terminan en la simple defensa de posiciones personales y actitudes viscerales que afectan todos los otros elementos estructurales, científicos y tecnológicos. En un ambiente de recursos restringidos, se debe velar por el diálogo y la comunicación constructiva.

$\mathrm{ML}$ / Estoy convencido de que en todas las universidades hay un gran potencial para contribuir a la innovación y la competitividad del país. En ese contexto, las universidades públicas y privadas cuentan con condiciones para coadyuvar la innovación y la competitividad del país, siempre tomando en consideración las limitaciones presupuestarias y de inversión en esta temática; sin embargo, vale la pena mencionar que somos el único país en el mundo, en pleno siglo XXI, que no cuenta con un organismo rector del sector ciencia, tecnología e innovación; lo cual produce la ausencia de políticas públicas y de una estrategia nacional de ciencia, tecnología e innovación. En consecuencia, hacen falta las condiciones políticas, la institucionalidad, la infraestructura científica tecnológica y el financiamiento respectivo para este sector $(I+D+i)$.

5. CT/ ¿Cuenta la universidad con el capital humano: competencia cognitivas, habilidades, destrezas y actitudes para incorporarse al proceso de I+ D + i? 
RZI Definitivamente sí. El problema no es de capacidad, es de actitud. Lejos de buscar la sinergia de nuestras ideas, nos confrontamos en posiciones viscerales que no aportan unas a otras y que más bien desgastan el sistema. Gastamos mucha energía en tratar de imponer nuestra razón, en lugar de escuchar a nuestros colegas.

ML/Definitivamente que sí. Las universidades públicas y privadas cuentan con el capital humano que posee el conocimiento, las competencias y las habilidades necesarias para incorporarse a procesos de investigación, desarrollo e innovación ( $(+\mathrm{D}+\mathrm{i})$; no obstante, requieren de apoyo institucional, apoyo moral, apoyo financiero y reconocimiento dentro de la comunidad universitaria, de tal manera que se cree un compromiso, deseo y amor por la investigación científica, el desarrollo tecnológico y la innovación.

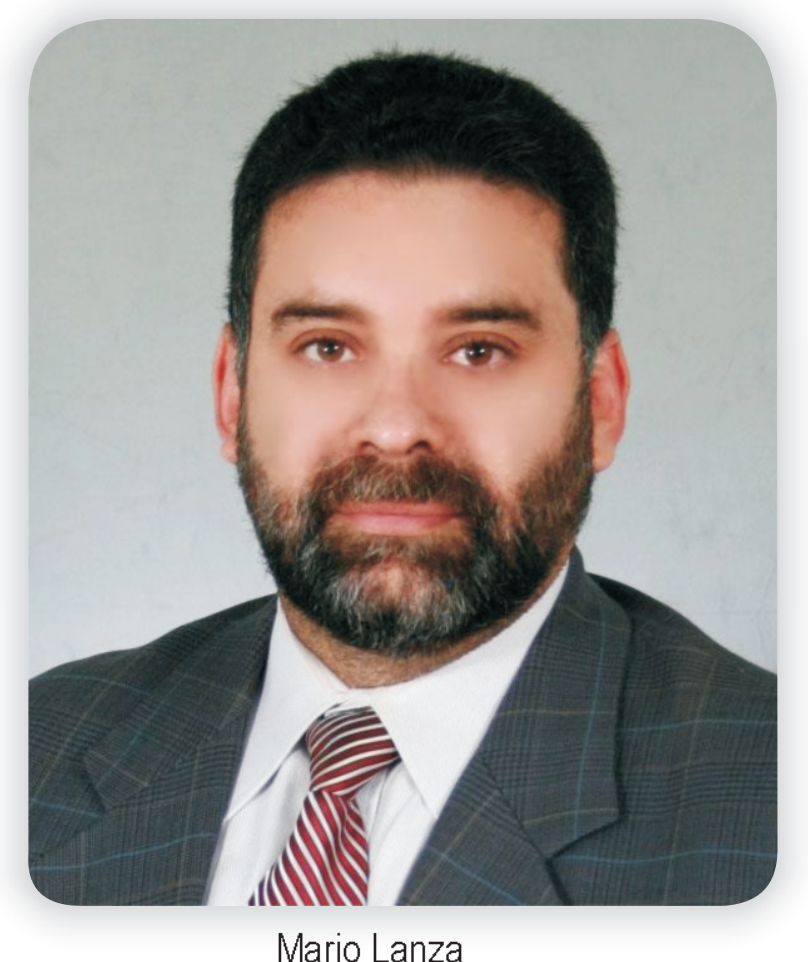

6. CT/ Es ampliamente conocido que cuando un país aspira a ser competitivo debe hacer una excelente gestión del capital humano, pero en este entramado de competencias, ¿cuáles deben privilegiarse? 
RZI Consideramos que algunas de las más importantes son la inteligencia estratégica, creatividad útil y la administración de recursos. Sin embargo, es muy difícil escoger, pero yo comenzaría con inteligencia estratégica y el desarrollo de una visión común de todos, complementando con la creatividad y la autoestima. La mejora de la comunicación y el manejo de recursos se convierten en elementos clave.

ML/ A nuestro juicio deben destacarse la inteligencia estratégica, trabajo en equipo, adaptación al cambio, capacidad de análisis, solución de problemas, inferencia y análisis conceptual, ética, capacidad para generar y transferir el conocimiento científico y tecnológico. 